\title{
Vision and Strategic Objectives for Sustainable Development of the Apuseni Mountains Mining Settlements
}

\author{
Veronica Constantin ${ }^{A}$, Vasile Surd ${ }^{B *}$, Camelia-Maria Kantor ${ }^{\mathrm{C}}$ \\ Received: April 15, 2014 | Revised: July 29, 2014 | Accepted: October 30, 2014
}

\begin{abstract}
The restructuring of the mining sector in Romania since 1989 has had extremely serious social, economic and environmental consequences for the mining settlements. Following the mine closure programs and socio-economic and environmental regeneration efforts the situation has only slightly improved, the settlements being still very vulnerable in terms of quality of life and prospects for sustainable development. In this paper the authors have developed a vision for sustainable development of the Apuseni Mountains mining areas that would support policy writing and lead to the identification of appropriate solutions for socio-economic and environmental development of the studied area.
\end{abstract}

Key words: mining area, planning models, sustainable development, Apuseni Mountains, Romania

\section{Introduction}

This paper outlines a concept of sustainable and strategic development based on identified axes and directions of action for the mining settlements in the Apuseni Mountains. The authors selected eleven areas previously used in the exploitation of metal deposits, more precisely seven sites used for exploitation of gold, silver, and polymetallic deposits located in the Golden Quadrilateral (Alba and Hunedoara), two for exploitation of iron ores (Cluj county), a gold mine with uranium resources (Alba and Bihor counties), and a mine for bauxite exploitation (Bihor county) (Figure 1).

The concept of sustainable development formed over several decades and especially became popular in the past two decades due to numerous international scientific debates and various political (propaganda), economic (scarcity), and even religious (welfare society) approaches in the context of globalization (Kibert, et al., 2011). Sustainable development is defined as "development that meets the needs of the present without compromising the ability of future generations to meet their own needs" (Brundtland Report, 1987). This concept is based on finding the balance and harmony between economic sustainability, social sustainability and environmental sustainability (Elkington, 1997), key concepts identified by Dyllick and Hockerts (Gilbert, Schipper, 2010). In essence, sustainable development means ensuring a continuous, and constant development based on five strategic pillars: economic growth, social justice, a healthy environment, cultural identity and institutional development or partnership for sustainable development. Thus, the concern for the balance between economic growth and social welfare has become a political and managerial challenge of over the last 150 years (Dyllick, Hockerts, 2002).

The concept of sustainable development is the result of an integrated approach to policy and decision making, where environmental protection and long-

\footnotetext{
A The Regional Development Agency Centre, 12 Decebal Str., Alba Iulia, Alba County, Romania; veronica.constantin7@yahoo.com

B Babeş-Bolyai University, Faculty of Geography, Centre for Research on Settlements and Urbanism, "Babes Bolyai" University, Cluj Napoca, Romania; vsurd@geografie.ubbcluj.ro

c Claflin University, School of Humanities \& Social Sciences, Department of History \& Sociology, 400 Magnolia St., Orangeburg, South Carolina, USA; ckantor@claflin.edu
} 


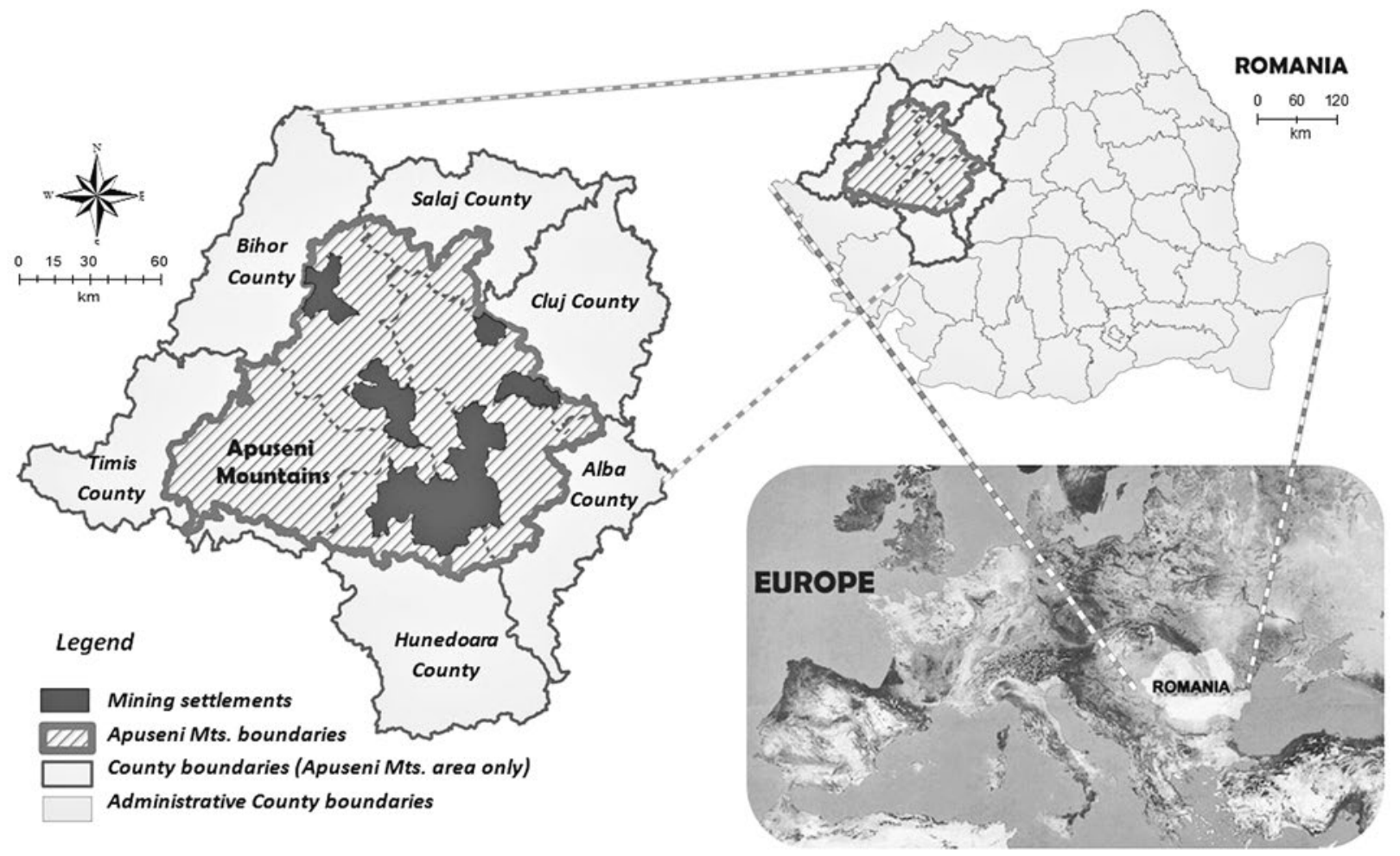

Figure 1. Geographic location of the Apuseni Mountains' mining settlements and the position of the investigated area in Romania

term economic growth are seen as complementary and interdependent (National Sustainable Development Strategy Romania 2013-2020-2030).

Practically, the concept of sustainable development requires an integrated approach to economic, social, environmental, cultural, and institutional local development projects as well as a participative approach where the end beneficiaries, the citizens, become involved in the whole process of planning and project implementation. In this particular scenario where the study area includes mining sites it is also important to consider sustainable development that emphasizes an adaptation of the economic policies to the operating parameters of the natural environment components (Mazilu, 2009, 2007, 2005) that would ensure the reduction (or even ending) of the aggression on the natural environment.

Up to date several studies that focused on sustainable development of the Apuseni Mountains mining areas discussed a number of issues ranging from $r u$ ral development (Barbu, 2005, Abrudan, Turnock, 2006, Sandu, et al., 2009), human development and social disparities (Erdeli, 2000, Surd, Zotic, 2003, Sandu, 2010, Butiu, Pascaru, 2012),economic development (Ciomac, Popa-Necşa, 1936, Dragan, 2013), urban regeneration (Muntean, Constantin, 2008),or mining and metallogenetic potential (Popescu, et al., 1995, Popa, 1999 ).

\section{Goal}

The main purpose of this research was to develop a concept of sustainable development for the settlements located in the mining areas of the Apuseni Mountains based on seven priorities. The resulting concept of sustainable development is intended as a tool for the local development policy and decision making process. In this paper we tried to find answers to the most important questions related to the proposed concept of integrated sustainable development strategy, such as:

- What are the strategic directions for sustainable development of the mining areas of the Apuseni Mountains?

- What should be the short, medium, and long term objectives in the process of sustainable development of the mining areas of the Apuseni Mountains?

- What are the concrete solutions for sustainable development of the mining areas of the Apuseni Mountains?

\section{Methodology}

The strategic concept of sustainable development of the settlements located in the mining areas of the Apuseni Mountains was based on:

- Geographical knowledge and analysis of the socioeconomic and environmental development of the mining areas located in the Apuseni Mountains; 
- Discussions with local and regional actors and analysis of information obtained during meetings with representatives from some municipalities, mining companies, businesses, or with educational experts in mining, environment, economy, demography, geology, etc. which operate in the geographic area of the Apuseni Mountains;

- SWOT analysis of the mining areas of the Apuseni Mountains;

- Experience in regional planning for sustainable development and reducing disparities;

- Consultation of major public documents at national and regional level regarding planning and development of the territory, economic development, human resource development and environmental sustainability;

- Analysis of European Union directives on territorial, social and environmental cohesion;

- Documentation on the strategic directions of sustainable development in Europe, especially within the next 10 years

- Scientific literature related to best models proposed for restructuring of mining areas;

- Knowledge of best practices on planning and sustainable development of mining areas in EU countries.

More specifically, in terms of the selected documents that pertain directly to decision making for the mining areas of the Apuseni Mountains, this proposed concept of integrated development is consistent with both the principles of political cohesion of the European Union policy 2007-2013 as presented in the Community Strategic Guideliness and EUROPA Strategy 2020, and strategic documents at the national and regional level such as the National Strategy for Sustainable Development of Romania 2013-2020-2030, National Strategic Guideliness for Sustainable Development of the Carphatians 2014-2020, National Strategy for Regional Development 2014-2020, Plan for National Territory Development, National Strategic Plan for Rural Development 2014-2020, National Programme for Rural Development 2014-2020, Mining Industry Strategic Plan for the period 2006-2020, Sectorial Operational Programme for Economic Competitiveness 2007-2013, National Programme for Mine Closure and Mining Areas Reconversion, National Anti-Poverty and Social-Inclusion Plan 2002-2012, Sectorial Operational Programme for Human Resources Development 2007-2013, National Strategy and National Action Plan for the Management of Contaminated Sites in Romania, National Strategy for Ecotourism Development in Romania, and the Plan for Apuseni Mountains Area Development.

Thus, based on the above-mentioned directions the authors have outlined a vision for sustainable devel- opment of the settlements located in the mining areas of the Apuseni Mountains. The main objective was to identify the functionality of our concept if applied to a network of settlements within a larger goal of improving the economic and living conditions of the residents.

\section{Vision and strategic objectives for sustainable development of the studied mining settlements}

Starting from the assumption that a strategy of sustainable development is the result of collective effort, the authors propose a concept-strategy of sustainable development for the mining settlements of the Apuseni Mountains. The intent is to provide both a vision of integrated development within the context of major challenges at national and European levels, and pragmatic aspects that can represent a template for decision-makers (ideas and concrete proposals for projects, funding resources eligible for the proposed action, etc.).

The development of such a concept-strategy of sustainable development for the mining settlements of the Apuseni Mountains is the result of a summary of conclusions drawn from both scientific research and practice and translated into possible solutions for sustainable development. At the same time, the proposed concept - strategy was correlated with major policies and strategic, programmed or developmental documents.

Generally, a vision of sustainable development implies a long planning process in which decisions focused on territorial, socio-cultural, economic and environmental assessments are based on best available information and coordinated at the local, regional, national, or even global level. Sustainable development brings the vital evaluation categories in balance and facilitates the dialogue and the integrated actions of interest groups and stakeholders involved in the process. It requires consideration of differences in spatial and temporal scales and an understanding of the complex interdependencies between economic, environmental, social and cultural factors (Campbell, 1995). Therefore, a sustainable development strategy is a functional overview of economic, environmental, and general wellbeing of stakeholders.

Mining activities imprint theirs special features into the landscape (Zhang, et al., 2011). Therefore, vulnerability becomes their dominant feature (Fabbri, et al., 2002). Thus, a vision for sustainable development of these areas requires a complex approach that must consider a number of issues addressed in an integrated manner, such as time frames (actual period of exploitation of resources, the mining restructuring period, and 
the post-mining period) or variation in institutional strength or involvement due to changing politics.

In contrast to the revitalization of the post-mining regions of Central Europe, mining activities in Romania, and implicitly our research area, the Apuseni Mountains, have diminished considerably in the last 20 years, which created social, economic and environmental imbalances. With this in mind, when selecting the relevant information needed for shaping the strategic concept of sustainable development, the authors have focused on formulating directions and identifying actions aimed for revitalization and redevelopment of the settlements located in these mining areas.

Consequently, the first step was to identify five strategic pillars of sustainable development that focus on maximizing the added value of products or services created by the community by obtaining a synergistic effect of:

- Increased economic growth (technology, retraining, human resource's active attitudes toward the labor market);

- Social equity (involving both social responsibility of policy makers, administrative and sectorial authorities and corporate citizens, or of the business environment, as well as increased accountability of those benefiting from investments and services provided by community);

- Conservation and environmental protection (community awareness creation process based on ecology and integrated management systems);

- Local cultural identity (including the creation and promotion of community trade marks);

- Institutional development (so called "good governance" which involves building intra and inter sectorial and administrative cooperation frameworks, public-private partnerships, participatory methods of development and implementation of local development policies).

\section{Vision of integrated development of the settlements located in the mining areas of the Apuseni Mountains}

The proposed model involves transforming selected mining areas into attractive areas, favorable for regional social and economic development. This can be mainly done by replacing the current dependence on mining activities with other foci.

In essence, the vision of rehabilitation and development of the mining areas located in this Carpathian space was based on three key directions:

- Sustainable development principles formulated and applied at the national and European level;

- Reasonable correlation of the county, regional, national, and European policies and public programs of development in terms of territorial, social, economic and environmental planning with appropriate sustainable development practices and directions;

- Identifying development solutions based on available resources (not exclusively mineral) and the existent potential and opportunities offered by the area, which could represent the starting point in shaping a development model based on an optimistic scenario.

Starting from this vision, an integrated approach is needed when shaping the concept-strategy of sustainable development of the settlements located in mining areas that would act as an useful tool for improving the current policies for sustainable development and territorial, social, economic, and environmental planning. Also, as mentioned before, the goal would be to identify appropriate solutions and facilitate decision making at local, county, and regional level for the institutions responsible for the development of these vulnerable areas. Figure 2 identifies priority axes that could represent a framework, orientation, and motivation for defining and generating development strategies based on post-mining potentials of the area. It is important mentioning that each axis should receive equal attention, but become the major focus of its own level when all the previous conditions are met. 


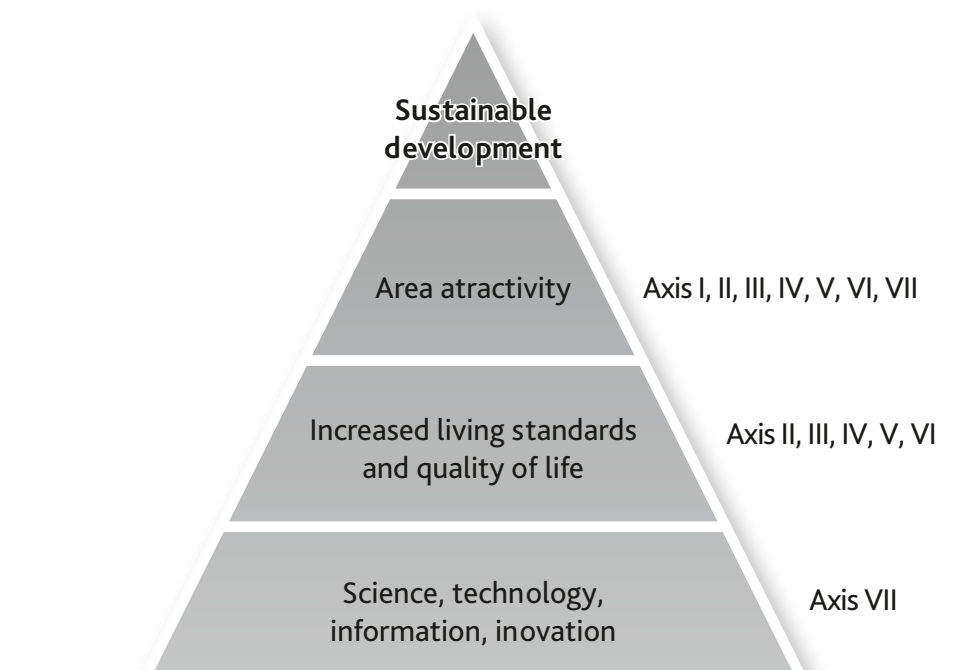

Valorification of resources potentional and development opportunities as well as risk reduction and mitigation of the gaps induced by natural and anthropic phenomena

Efficient management of all categories of available resources starting from the knowledge and continual updating of information through an information system

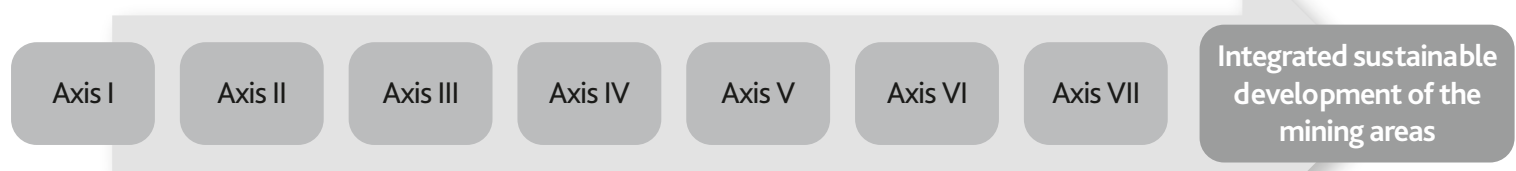

Figure 2. Priority axes correlation as part of the long-term sustainable development strategy of the Apuseni Mountains mining areas 


\section{Conclusions}

Within the still ongoing process of European Union integration, Romania is still learning and adjusting its strategies based on the European Union's model of "unity in diversity" and its own economic, cultural, and environmental heritage. Former areas reliant on mining activities are even more vulnerable than others to the new changes, having witnessed economic decline and environmental damage. Thus, these particular areas are in greater need for structural changes. Our vision of sustainable development for the Apuseni Mountains mining does not solve and specifically point to all of the problems, but makes a valuable contribution to current national and international efforts to restructure and rebuild post-mining areas. The present paper points to the need to make an integrated development strategy and a feasible common plan with measurable indicators as a major national, regional, and local priority.

Following the analysis and in depth documentation of existent literature and data sources, when looking for best solutions for sustainable development, regeneration and planning of the mining areas it was concluded that there are at least three key issues impacting on the successful transformation of a vulnerable and degraded area (in many ways) into an attractive and economically developed one, namely:

- Development of strategically integrated long-term projects that include a larger vision and a more integrative approach to solving major issues rather than simply implementing short term projects;

- Effective resource management and planning for conservation and sustainable utilization of the area specific resources;

- Involving all relevant stakeholders (local authorities, business environment, research environment, nongovernmental organizations), and especially the local population in the process of sustainable development.

\section{References}

Abrudan, I., Turnock, D. 2006. A rural development strategy for the Apuseni Mountains, Romania, GeoJournal 46 (3), 319-336.

Barbu, C.M. 2005. Possible support policy for agricultural and rural space sustainable development in Romania (In Romanian with English summary), Matrix Rom, Bucharest.

Butiu, C.A., Pascaru, M. 2012. Applied Sociology and Human Resources Development Strategies. A Project in Apuseni Mountains, Romania, Journal of Community Positive Practices 1/2012, 51-70.

Campbell, A. 1995. Mission, vision and strategy development, The Financial Times Handbook of Management, FT/Pitman Publishing, St Crainer.
Ciomac, I.L., Popa-Necşa, V. 1936. Apuseni Mountains. Research on the economic status of the Apuseni Mountains. (In Romanian), Tipografia ziarului „Universul”, Bucharest.

Dragan, M. 2013. The Reorganization of Economic Activities in the Apuseni Mountains, Rev. Roum. Geogr./Rom. Journ. Geogr. 57 (1), p.55-62, Bucharest. Dyllick, T., Hockerts, K. 2002, Beyond the business case for corporate sustainability, Business Strategy and the Environment 11, 130-141.

Elkington, J. 1997. Cannibals with Forks: the Triple Bottom Line of 21st Century Business, Capstone Publishing, Oxford.

Erdeli G. 2000. Geo-demographic trends in rural Romania, Post-communist Romania: Geographical Perspectives, Liverpool Hope Press, Liverpool, Great Britain, 67-74.

Fabbri, A. G., Woldai, T., Babiker, I.S., Kitutu Kimono, M.G., Homola, V. 2002. Land-Use Change and Vulnerability as a Result of Coal Mining Activities, Deposit and Geoenvironmental Models for Resource Exploitation and Environmental Security Nato Science Partnership Subseries: 2 (closed) Volume 80, 305-344, DOI: 10.1007/978-94-010-0303-2_16, ISBN 978-1-4020-0990-7, Springer Netherlands.

Gilbert, S.A.J., Schipper, R. 2010. A Maturity Model for Integrating Sustainability in Projects and Project Management, University of Applied Sciences, Utrecht, Netherlands, Available at http://www. hu.nl/ /media/HU-PORTAL/Images/Duurzaam/ Description.ashx

Last accessed: May 2, 2014.

Kibert, C. J., Thiele, L., Peterson, A., Monroe, M. 2011. The Ethics of Sustainability, Available at http:// www.cce.ufl.edu, Last accessed: May 2, 2014.

Mazilu, M. E. 2009. The ecological component of the lasting development, International Conference on Sustainable Development of the Balkan Area: Vision and Reality, Alba Iulia, Book 1, vol. 10, 131-136, No.1135/26.07.2007.

Mazilu, M. E. 2007. Environment-economics- sustainable industrial development (In Romanian with English summary), Scientific Journal of Information and Ecological Culture, No. 3 June 2007, ISSN: 810-9551, 45-48.

Mazilu, M. E. 2005. For environmental ethics (In Romanian), Scientific Journal of Innformation and Ecological Culture 3 (21), 33-34.

Muntean M, Constantin, V. 2008. Zlatna town in the context of urban regeneration (In Romanian), PANGEEA in AETERNITAS, No. 8, Alba Iulia, p. 4552, ISSN 1841-1517.

Popa, A. 1999. Past and future of the Apuseni Mountains gold mining (In Romanian), Mining Revue, No. 3. 
Popescu, Gh. C., Marinescu, M., Predeteanu, D. 1995. The Apuseni Mountains metallogenetic potentialpresent and future polutant? In Apuseni Mountains. Geoecologic study. (In Romanian), Society for Environmental Mineralogy and Petrography „L. Mrazec”, Bucharest.

Sandu, D., Voineagu, V., Panduru, F. 2009. Development of Romanian communes (In Romanian), National Institute of Statistics, Bucharest University, Bucharest.

Sandu, D. 2010. Social disparities in the development and regional politics in Romania (In Romanian), Bucharest University, Study on "Community capital investment in Romania", CNCSIS-ID 2086.

Surd, V., Zotic, V. 2003. The Demographic Risc in the Arieş Superior Basin, Studia, Cluj-Napoca, 407-446.

Surd, V., Zotic, V., Puiu, V., Moldovan, C. 2007. Demographic risk in the Apuseni Mountains (in Romanian with English summary), Presa Universitară Clujană, ISBN 978-973-610-626-2.

Zhang, J., Fu, M., Hassani, F., Zeng, H., Geng, Y., Bai, Z. 2011. Land use-based landscape planning and restoration in mine closure areas, Environmental Management, 02/2011, 47(5):739-50, DOI: 10.1007/ soo267-011-9638-z, PubMed

\section{Public documents}

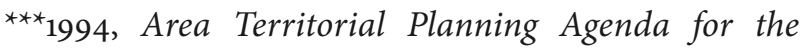
Apuseni Mountains, „MunţiiApuseni, URBANPROIECT Bucharest

*** 1987, Brundtland Report, "Report of the World Commission on Environment and Development. Our Common Future", United Nations.

${ }^{* * *}{ }_{2005}$, The Community Strategic Guidelines on Cohesion for the period 2007-2013, European Commission

*** 2010, E U R O P E 202 o. A European strategy for smart, sustainable and inclusive growth, European Commission

${ }^{* * *}$ Decision No. 829 from July 31st, 2002 regarding the approval of the National Anti-Poverty and Social Inclusion Plan, Romanian Government.
${ }^{* *}{ }_{2013}$, National Strategic Orientations for Sustainable Development of the Carpathian Mountains for the period 2014 - 2020, Ministry of Agriculture and Rural Development

${ }^{* * *}$ 2012, Spatial Planning of the National Territory, Ministry of Regional Development and Public Public Administration, Revised July 12, 2012

${ }^{* *}{ }_{2008}$, National Sustainable Development Strategy for Romania for the period 2013-2020-2030, Government of Romania Ministry of Environment and Sustainable Development and United Nations Development Program, National Centre for Sustainable Development, Bucharest.

${ }^{* * *}$ 2007, National Strategic Plan for Rural Development for the period 2007 - 2013, Ministry of Agriculture and Rural Development.

${ }^{* *} 2007$, Sectorial Operational Programme for Economic Competitiveness for the period $2007-2013$, Ministry of European Funding.

${ }^{* * *}$ 2005, National Programme for Mine Closure and Mining Areas Reconversion, Ministry of the Economy,

${ }^{* * *}$ 2007, Operational Sectorial Programme for Human Resources Development for the period 2007 - 2013, Ministry of Employment, Family, and Equal Opportunity.

${ }_{* * *} 2014$, National Strategy for Regional Development for the period 2014-2020, Ministry of Regional Development and Public Administration.

${ }^{* * *} 2014$, Strategy for Rural Development of Romania for the period 2014-2020, Ministry of Agriculture and Rural Development

${ }^{* * *} 2006$, Mining Industry Strategy for the period for the period 2006-2020, Ministry of the Economy.

${ }^{* * *} 2013$, National Strategy and National Action Plan for Management of Contaminated Sites, Ministry of the Environment and Climate Change.

***2010, National Strategy for Ecotourism Development in Romania Phase I and II, Ministry of Regional Development and Public Administration. 